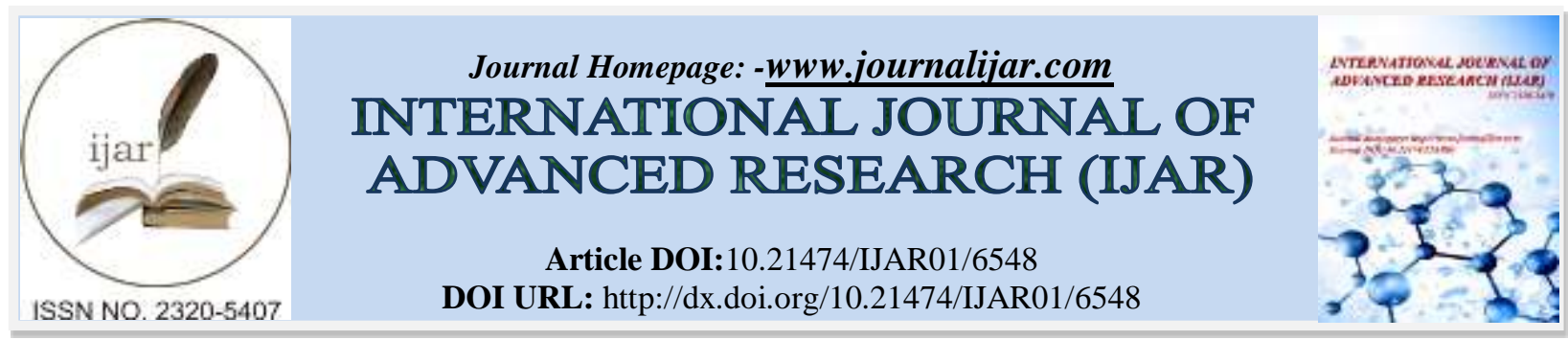

RESEARCH ARTICLE

\title{
INTERNET USAGE OF THE SHS STUDENTS OF LCUP AND ITS IMPACT ON THEIR HABITS AND ATTITUDES.
}

\section{Valdez, Janet R. ${ }^{1}$, Camara Melanie $C^{1}{ }^{1}$ and Dayao, Edna $F^{2}$.}

1. La Consolacion University Philippines Graduate School.

2. La Consolacion University Philippines College of Information Technology and Engineering.

\section{Manuscript Info}

Manuscript History

Received: 16 December 2017

Final Accepted: 18 January 2018

Published: February 2018

Keywords:-

Internet impact, Internet usage.

\begin{abstract}
Internet, as we know it at present, started to assemble a link between and among networks around the world. The advent of the world wide web (www) in the 1990s changed the lifestyle and norms of the computer-age generation. Its effects reverberated and took shape in the households, in the offices, and in the academic institutions. The excitement created by this technological innovation maneuvered a change in the life and time of its frequent users transforming their routine activities, habits, and attitudes. While the global population had admitted the influence of the Internet on its users, it was interesting to discover the impact of Internet usage in a particular locality. It would create an understanding of the locality and its population which could, in turn, aid in identifying plans, policies, and programs useful to the general public. The purpose of this research was to determine the impact of Internet usage on the senior high school students of La Consolacion University Philippines.
\end{abstract}

Copy Right, IJAR, 2018,. All rights reserved.

\section{Introduction:-}

The advent of the Internet in the 1990s with the introduction of the world wide web (www) generated a light of excitement among the users. It changed the way people look at the computer and the world. The computer gained popularity in various locations including the homes, offices, and schools. The growing number of Internet users, with 2,925,249,355 global Internet users in 2014 from a 14,161,570 users in 1993 (Netcraft and Internet Live Stats, as cited in Miller et al.,2015), conveyed the role it assumed in transformed technologically savvy millennials.

It was, therefore, noteworthy to determine the usage of the Internet among users and classify them as excessive Internet users: those who needed an increased amount of time on the Internet to achieve satisfaction, or average Internet users: those who used the Internet without sacrificing any of their routine activities. It was from the light of the preceding statement that Gupta and Sharma (2016) explored the relationship between the impact of Internet usage (excessive and average) on the quality of life among young adults and, later, found that the quality of life of average Internet users was comparatively better than that of the excessive Internet users. On the other hand, researchers studied the relationship of age, education, and Internet use, like in the study of Berner et al.( 2012) which revealed that Internet usage declined significantly with age and those with middle to higher education were using the Internet the most. Miller et al. (2015) revealed interesting statistics related to Internet use including time spent using digital and traditional media which meant that the time adults spent using digital media surpassed the 
time spent watching television (eMarketer, as cited in Miller et al., 2015); and adult use of the Internet, which rose from $52 \%$ in 2000 to $84 \%$ in 2015 where the largest population group belonged to the age range of 18 to 29 years, $96 \%$, followed by 30 to 49 years, 93\%, ( Internet \& American Life Project by Pew Research Center, as cited in Miller et.al., 2015). These figures showed the extent of Internet influence in the lifestyle of its users as shown by the online activities engaged in by the Internet users. The Center for the Digital Future at the University of Southern California revealed that $96 \%$ used the Internet for Email, 71\% Internet surfing without a specific destination, $60 \%$ looking for news online, and the rest engaged in finding product information conducting online banking or other financial services, instant messaging, playing online games, and searching for humorous content ( Miller et al., 2015). While users' fondness on the use of the Internet as the activities found on the world wide web gave them forms of entertainment, links, and networks, the medium of interaction, and global exposure to culture and trends, the Internet waved a caveat on matters of security and privacy. DeNardis (2014) discussed the entanglement of individual privacy, preservation of national security, and the arbitration of digital commerce and innovation.

It was the objective of this study to determine the impact of Internet usage on the habits and attitudes of the Senior High School Students of La Consolacion University Philippines. The results of the study could be utilized by the administrators and the teachers in preparing school, classroom rules and regulations, policies, pedagogical strategies, and plans to maximize the fullest potentials of the students.

\section{Statement of the Problems:-}

The main concern of the research was to find out the impact of Internet usage on the habits and attitudes of the senior high school students of La Consolacion University Philippines.

Specifically, the researcher aimed to find the answers to the following questions.

1. How often do the SHS students of LCUP stay longer on the Internet as intended?

2. What reasons caused the SHS students of LCUP to use the Internet?

3. What are the changes in the habits and attitudes of the senior high school students of LCUP?

4. What is the impact of Internet use on the habits and attitudes of the senior high school students of La Consolacion University Philippines?

\section{Methodology:-}

This descriptive research utilized a standardized instrument that produced quantitative data resulting from the responses to the survey questionnaire of one hundred (100) randomly selected senior high school students of LCUP. The procedures for data collection were as follows:

1. A letter was sent to the author of the standardized instrument requesting permission for the use of the survey questionnaire.

2. The questionnaire was modified to fit the details of the respondents and the location.

3. The questionnaire was reproduced and distributed to one hundred (100) randomly selected senior high school students at La Consolacion University Philippines..

4. The questionnaire was answered and collected during the day.

5. The responses were tabulated and interpreted.

\section{Results and Discussions:-}

Problem No. 1. Internet usage of the senior high school students of La Consolacion University Philippines:The senior high school students of LCUP had a five-hour school schedule. With the time spent at school, thirty per cent $(30 \%)$ of the students still found themselves always staying online longer than intended. Also, twenty-nine per cent $(29 \%)$ rarely; twenty-five per cent $(25 \%)$ occasionally; and sixteen per cent $(16 \%)$ of the students never stayed online longer as intended. These figures conveyed that the time spent on activities other than online activities of $30 \%$ of the students diminished due to Internet usage. Thus, we looked into the other activities of the senior high school students that could be affected by Internet usage, such as the time supposedly spent on studying school lessons, or the number of hours sleeping, or the time spent on household chores.

Problem No. 2. The reasons for the use of the Internet by the SHS students of LCUP:-

The primary reason for ninety-five percent $(95 \%)$ of SHS students of LCUP in the use of the Internet was information surfing for study and school work. Secondly, ninety-two per cent $(92 \%)$ of the students used the Internet for information surfing for personal interest. Thirdly, ninety per cent (90\%) of the students listened to music on the Internet. Moreover, the other reasons, in the order of importance, why the students of senior high school at LCUP 
used the Internet are: downloading music and movies from the Internet (89\%), Internet gambling (83\%), meeting new friends (80\%), E-mailing current friends $(78 \%)$, playing web games $(75 \%)$, talking in chat rooms $(74 \%)$, and watching TV on the Internet (73\%), It was interesting to note that sixty-eight per cent $(68 \%)$ of the students did not create or maintained a personal web page while sixty-five percent $(65 \%)$ did not access pornography or shopped online $(48 \%)$.

\section{Problem No. 3. The changes in the habits and attitudes caused by Internet usage of the SHS students of} LCUP:-

The preference of thirty-eight per cent $(38 \%)$ of the students occasionally changed prioritizing the excitement of the Internet rather than spending time with friends in person. Internet use rarely changed the habits and attitudes of the senior high school students of LCUP: checking the E-mail before something else that should be done (47\%), trying to hide how long time spent online (47\%), becoming defensive or secretive when anyone asks what is done online $(45 \%)$, the suffering of grades or schoolwork because of the amount of work spent online (43\%), fearing that life without the Internet would be boring, empty, and joyless (43\%), trying and failing to cut down the amount of time spent online $(43 \%)$, forming new relationships with fellow online users $(41 \%)$, complaining from others about the amount of time spent online $(41 \%)$, the suffering of job performance or productivity due to the Internet $(41 \%)$, blocking out disturbing thoughts about life with soothing thoughts of the Internet (41\%), feeling depressed moody or nervous when offline (41\%), neglecting household chores to spend more time online (39\%), anticipating to go online again ( $39 \%)$, using the Internet to escape from other problems in life (39\%), snapping, yelling, or acting annoyed if someone bothers while online (37\%), losing sleep due to late-nights log-ins (37\%), and saying "just a few more minutes" when online $(36 \%)$.

\section{Problem No. 4:- The impact of Internet usage on the habits and attitudes of the SHS students of LCUP}

The general mean average was 2.45 which reflected the 'occasional' impact of Internet use on the habits and attitudes of the senior high school students of LCUP. This meant that while the students always stayed online longer than intended, Internet use occasionally impacted the habits and attitudes of the students; therefore, it did not show an alarming scenario.

\section{Conclusion and Recommendations:-}

1. The Senior High School students of La Consolacion always stayed online longer than intended.

2. Almost all the students accessed the Internet for information surfing either for school and study purposes or personal interests.

3. Most of the students utilized the Internet for good entertainment: music, movies, and games.

4. Majority of the students shopped online.

5. In terms of popularity between Internet gambling and accessing pornography, the students opted Internet gambling.

6. Internet usage of the Senior High School students of LCUP did not cause an alarm on the change in the habits and attitudes of the students.

\section{References:-}

1. Berner, J., Rennemark, M., Jogréus, C., \& Berglund, J. (2012). Distribution of personality, individual characteristics and internet usage in Swedish older adults. Aging \& Mental Health, 16(1), 119-126.

2. Crystal, D. (2001). Language and the Internet. Cambridge: Cambridge University Press.

3. DeNardis, L. (2014). The Global War for Internet Governance. New Haven: Yale University Press.

4. Gupta, S., \& Sharma, R. (2016). The impact of internet usage (average/excessive) on quality of life among young adults.

5. Miller, R. K., Washington, K. D., \& Richard K. Miller \&, A. (2015). Consumer Use of the Internet \& Mobile Web 2016-2017. Loganville, GA: Richard K. Miller \& Associates. 